\title{
Expression analysis and biological characterization of Babesia sp. BQ1 (Lintan) (Babesia motasi-like) rhoptry-associated protein 1 and its potential use in serodiagnosis via ELISA
}

Qingli Niu' ${ }^{1}$ Zhijie Liu', Jifei Yang ${ }^{1}$, Peifa Yu' ${ }^{1}$, Yuping Pan ${ }^{1}$, Bintao Zhai ${ }^{1}$, Jianxun Luo ${ }^{1}$, Emmanuelle Moreau ${ }^{3}$, Guiquan Guan ${ }^{1 *}$ and Hong Yin ${ }^{1,2^{*}}$

\begin{abstract}
Background: In China, ovine babesiosis is one of the most important tick-borne haemoparasitic diseases of small ruminants. It has a significant economic impact, and several Babesia motasi-like isolates have been recently shown to be responsible for ovine babesiosis in this country.

Methods: Full-length and C-terminal-truncated forms of the rap-1a61-1 gene of Babesia sp. BQ1 (Lintan) were cloned into the pET-30a plasmid and subsequently expressed as His-fusion proteins. The resulting recombinant RAP-1a proteins (rRAP-1a61-1 and rRAP-1a61-1/CT) were purified and evaluated as diagnostic antigens using Western blot analysis and ELISA. The native Babesia sp. BQ1 (Lintan) RAP-1 protein was recognized using Western blots and IFAT by antibodies that were raised in rabbits against rRAP-1a61-1/CT. The specificity, sensitivity and positive threshold values for rRAP-1a61-1/CT in ELISA were evaluated.

Results: Cross-reactivity was observed between rRAP-1a61-1/CT and positive sera for Babesia sp. BQ1 (Lintan), Babesia sp. BQ1 (Ningxian) and Babesia sp. Tianzhu isolates obtained from infected sheep. At one week postinoculation, a significant increase was observed in the amount of antibodies produced against RAP-1a, and high levels of antibodies against RAP-1a were observed for 3 months (at 84 days p.i.). A total of 3198 serum samples were collected from small ruminants in 54 different regions in 23 provinces of China. These samples were tested using ELISA based on the rRAP-1a61-1/CT protein. The results indicated that the average positive rate was $36.02 \%$.
\end{abstract}

Conclusions: The present study suggests that rRAP-1a61-1/CT might be a potential diagnostic antigen for detecting several isolates of $B$. motasi-like parasites infection.

Keywords: Babesia sp. BQ1 (Lintan), Rhoptry-associated protein, Biological characterization, Diagnosis

\footnotetext{
*Correspondence: guanguiquan@caas.cn; yinhong@caas.cn

'State Key Laboratory of Veterinary Etiological Biology, Key Laboratory of

Veterinary Parasitology of Gansu Province, Lanzhou Veterinary Research.

Institute, Chinese Academy of Agricultural Science, Xujiaping 1, Lanzhou,

Gansu 730046, P. R. China

Full list of author information is available at the end of the article
} 


\section{Background}

Ovine babesiosis is one of the most important tickborne diseases of small ruminants. This disease has been described in many countries throughout Asia, Europe and Africa [1]. A phylogenetic tree based on the sequence of the 18S rRNA gene showed that Babesia species belonging to the following four groups are responsible for babesiosis in small ruminants: $B$. ovis, $B$. motasi which are a European and a Chinese clade (B. motasi-like), and the Babesia sp. Xinjiang and B. crassa [2-7]. In the B. motasi Chinese clade (B. motasi-like), six Babesia isolates (Babesia sp. BQ1 (Lintan), Babesia sp. BQ1 (Ningxian), Babesia sp. Tianzhu, Babesia sp. Hebei, Babesia sp. Madang and Babesia sp. Liaoning) have been recently reported in the Gansu, Hebei and Liaoning provinces of China. These isolates can be classified into one or more sub-groups according to their phylogenetic relationships, which have been reconstructed based on several (18S rRNA, ITS, 28S, rap-1) phylogenetic markers [7-12].

Currently, the strategy for controlling babesiosis is based on chemotherapy against either the vector or the parasite. Several compounds are used, but mainly ivermectin is used against ticks and imidocarb against Babesia. Several new anti-Babesia drugs (Triclosan, Nerolidol, Artesunate and Atovaquone) are also used to control and treat babesiosis [13]. However, this strategy has many drawbacks, such as drug-resistance, the presence of drug metabolites in the milk and meat, and high toxicity to the animals themselves. Optimal treatment methods, including those with biological activity against ticks and vaccines that target either the ticks or the parasites, have been extensively studied. But only live attenuated vaccines are currently used in some countries, and no producing or testing recombinant or subunit vaccines have been available to prevent babesiosis so far [13-16].

Clinical symptoms of babesiosis usually include fever, anemia, and hemoglobinuria and can lead to death in severe cases, which become apparent when merozoites from the Babesia invade and replicate within host erythrocytes, resulting in detectable parasitemia [17]. During the process of erythrocytic invasion, some of the proteins, including apical membrane antigen-1 (AMA-1), rhoptry-associated-protein-1 (RAP-1), and spherical body proteins (SBP-1, 2, 3), are secreted by the apical organelles (rhoptries, micronemes and dense granules). Although the functions and implications of these proteins for vaccines designed against Babesia infections have been described mainly in B. bigemina and B. bovis, these data may form a basis for developing a recombinant vaccine against other Babesia infections [17].

RAP-1 is an immunogenic protein that is approximately $40-60 \mathrm{kDa}$ in size. It is localized in rhoptries and has been characterized in all Babesia species examined so far ( $B$. bovis, B. bigemina, B. divergens, B. canis, B. ovis, $B$. motasi-like, B. orientalis and B. gibsoni) [12, 18-23]. RAP1 was detected at all asexual growth stages [24] and was expressed during the sporozoite stage by a RAP-1 specific antisera that was obtained from rabbits immunized to neutralize the binding of sporozoites of $B$. bovis to erythrocytes [25]. Moreover, the role of RAP-1 in the erythrocyte invasion process has been studied in vitro during parasite adhesion to erythrocytes, and experiments have been performed to study the inhibitory effect of RAP-1specific antibodies on growth and invasion [24-26]. Immunization with native and recombinant RAP-1 protein from B. bovis and B. bigemina also induced immunity and protected animals upon challenge [27-29]. These studies strongly support the notion that RAP-1 plays a functional role in the biology and development of Babesia parasites and represents a potential candidate for the development of recombinant vaccines against babesiosis [30-33].

Rap-1 was characterized and found to be present as multiple gene copies that are arranged in a tandem, head to tail manner in all Babesia species. In sheep Babesia species, the rap-1 locus of the $B$. motasi-like gene is similar to the locus of $B$. bigemina: in both species, three different isoforms (rap-1a, rap-1b and rap-1c), 5 identical rap-1b copies and a single rap-1c located at end of locus have been described [12, 34]. Two rap-1a classes named rap-1a61 and rap-1a67 have been described, and each class is represented by two close variants (rap1a61-1 and rap-1a61-2; rap-1a67-1 and rap-1a67-2) in Babesia sp. BQ1 (Lintan) [34]. Polymorphisms were limited to three nucleotide positions in the rap-1a61 copies (rap-1a61-1, -2, -3) and were found in the rap-1 locus of Babesia sp. BQ1 (Lintan) (rap-1a61-1 and -2), Babesia sp. BQ1 (Ningxian) and Babesia sp. Tianzhu (rap-1a612 and -3$)[12,34]$. According to a phylogenetic tree that was constructed based on the rap-1 gene sequences, the B. motasi-like group can be separated into two subgroups: one that consists Babesia sp. BQ1 (Lintan and Ningxian) and Babesia sp. Tianzhu and another that contains Babesia sp. Hebei [12].

The rap-1a gene has been found in all Babesia species and shows highly conserved protein features (30-45\% identity among species), suggesting that this gene plays an important role in the RBC invasion process [35]. Moreover, RAP-1a, in Babesia has been widely used as a vaccine candidate and diagnostic antigen [21, 29, 36, 37]. The expression, biological characterization and immunogenicity of RAP-1a in sheep Babesia species have not been extensively studied. In the present study, we cloned and expressed RAP-1a and then detected the presence of antibodies directed against native and recombinant forms of RAP-1a during the course of infection. To evaluate the potential of using recombinant RAP-1a as a diagnostic antigen, we compared the diagnostic potential 
of full-length and truncated C-terminal recombinant Babesia sp. BQ1 (Lintan) RAP-1a proteins using via Western blot analysis. We discuss our results in combination with the outcomes of previous studies.

\section{Methods}

\section{Parasites}

The original isolates of the B. motasi-like group, including Babesia sp. BQ1 (Lintan), Babesia sp. BQ1 (Ningxian), Babesia sp. Tianzhu and Babesia sp. Hebei, were obtained from infected sheep and then cryopreserved in liquid nitrogen at the Vector and Vector-borne Disease (VVBD) Laboratory of the Lanzhou Veterinary Research Institute (LVRI) (CAAS Lanzhou, China) $[3,4,6]$.

\section{Sera}

Positive sera were obtained from five different breeds of sheep (two "Tan mutton" Chinese sheep, including No. 3216 and 2007, and three "Vendean" French sheep, including No. 3309, 3533 and 3446) that were infected with Babesia sp. BQ1 (Lintan). Immune-positive sera were obtained from sheep Nos. 08026, 08040 and 08020, which were infected by Babesia sp. BQ1 (Ningxian), Babesia sp. Tianzhu and Babesia sp. Hebei, respectively, and immune-positive sera were obtained from sheep No. 3201, which was infected with Babesia sp. Xinjiang, as previously described [38]. These serum samples were used to evaluate cross-infection and antibody kinetics. Positive sera from sheep that were experimentally infected with Theileria luwenshuni, T. uilenbergi and Anaplasma ovis or bovine B. bovis and B. bigemina were used as the controls to evaluate cross-reactivity.

Fifty serum samples were collected from five sheep (312 wpi) that were experimentally infected with Babesia sp. BQ1 (Lintan). In total, 141 sera and anticoagulated blood samples were collected from sheep in the Xinjiang, Henan and Gansu provinces of China. Genomic DNA was purified from blood samples and tested using specific PCR primers, and 141 genomic DNA samples were found to be specifically positive for Babesia sp. BQ1 (Lintan) in the sequencing analysis (data not shown). The sera samples $(n=141)$ that corresponded to these genomic DNA samples were selected as the positive serum samples. A total of 191 sera were used as positive samples to evaluate the sensitivity of the ELISA, and a mixture of these sera was used as the positive control serum.

Sera were collected from 492 lambs that were purchased from a Babesia-free region in Jingtai country (Gansu province of China) from 2010 to 2015. After nested PCR tests were performed, none of the samples tested positive, and a mixture of these serum samples was used as the negative control serum to evaluate the specificity of the ELISA.
A total of 3198 serum samples were randomly collected from clinically healthy sheep from 54 different locations in 23 Chinese provinces between 2010 and 2015 (Fig. 1). All blood samples were collected in nonanticoagulation tubes and transported to the laboratory while on ice. The serum was then separated and stored at $-20{ }^{\circ} \mathrm{C}$ until further use.

\section{Ethical approval}

This study was approved by the Animal Ethics Committee of the Lanzhou Veterinary Research Institute at the Chinese Academy of Agricultural Sciences. All animals used in this study were handled in accordance with the Animal Ethics Procedures and Guidelines of the People's Republic of China.

\section{Cloning of the full-length and the C-terminal truncated RAP-1a61-1 genes}

Genomic DNA was extracted from infected blood samples obtained from sheep infected with Babesia sp. BQ1 (Lintan) using a QIAamp DNA Blood Kit (QIAGEN, Maryland, USA) according to the manufacturer's instructions. These DNA samples were used as the templates for PCR. The oligonucleotide primers that were used to amplify the full-length and C-terminal-truncated rap-1a61-1 genes were designed based on the DNA sequence of Babesia sp. BQ1 (Lintan) RAP-1a61-1 (GenBank accession number KC953701) and modified to include either Xba I and BamH I or Nde I and Hind III (New England BioLabs) enzyme restriction sites (underlined below) at their $5^{\prime}$ end. The following primers were used: RAP-1a61-full-F: 5'-CGC TCT AGA -GT ACG CCA TTA CCA CCG TTC-3', RAP-1a61-full-R: 5'-GCC GGA TCC GAG CCA CGA ATC ATC GGA TTC-3', RAP-1a61/CTF: 5'-CGC CAT ATG ACC ACG GTG ATG CCC GAG-3', and RAP-1a61/CT-R: 5'-GCC AAG CTT GAG CCA CGA ATC ATC GGA-3'. The PCR products were cloned into the pUC57 vector according to the manufacturer's instructions (Genscript). The inserts were sequenced using vector primers. Representative plasmids were selected and digested using either $\mathrm{Xba}$ I and BamH I or NdeI and HindIII restriction enzymes and subsequently cloned into digested pET-30a expression vectors (Genscript) according to the manufacturer's instructions. This resulted in the generation of the recombinant plasmids pET-30a-RAP1a61-1 and pET-30a-RAP-1a61-1/CT, which contained the full-length gene (1359 bp, except for signal peptide sequence) and the C-terminal-truncated fragment (450 bp), respectively. Both of the cloned RAP-1a proteins were tagged with histidine.

Expression and purification of the recombinant proteins To express the recombinant proteins, both pET-30a-RAP1a61-1 and pET-30a-RAP-1a61-1/CT were transformed 


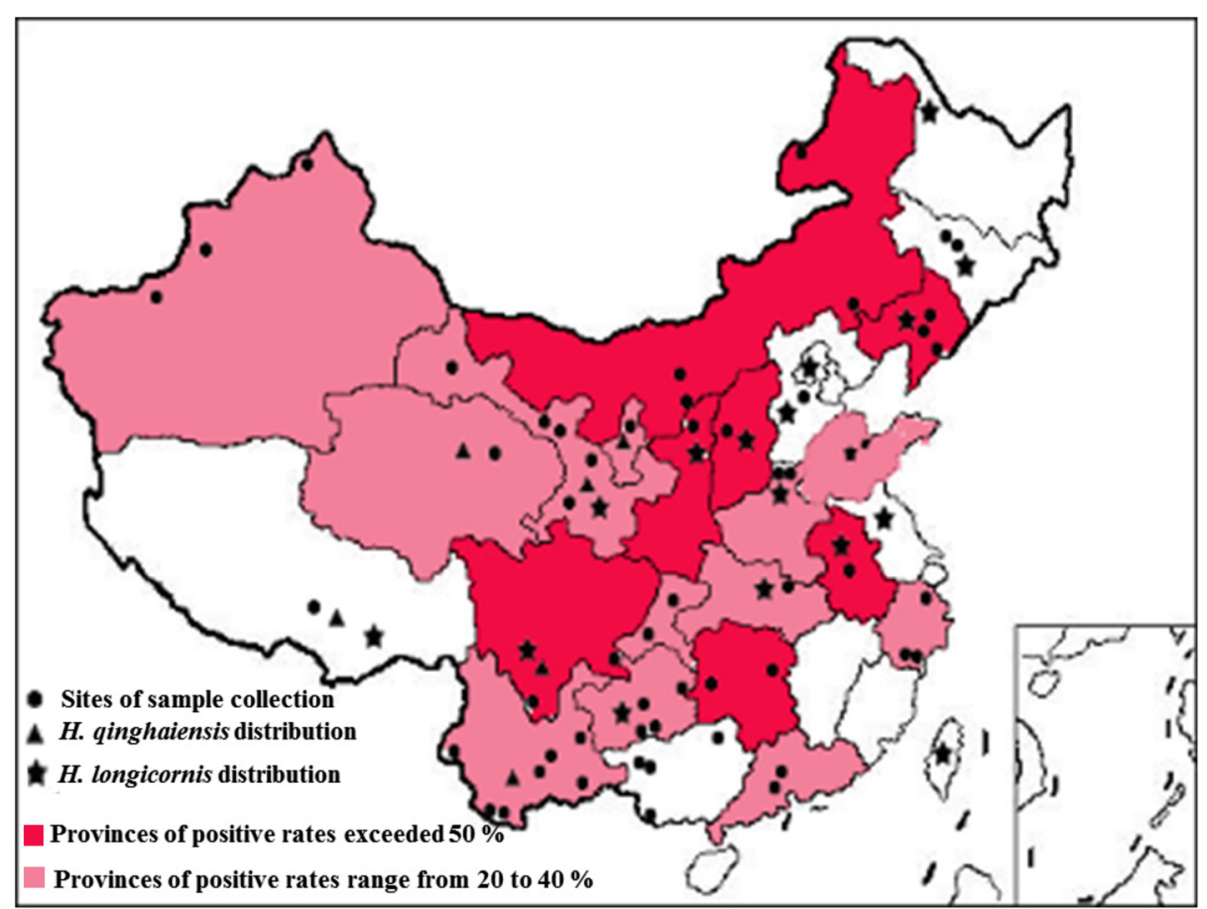

Fig. 1 The geographical distribution of the B. motasi-like sp. that was identified in this study and the distribution of Haemaphysalis spp. in China. The positive rates exceed $50 \%$ indicated with deep red, and the positive rates ranged from 20 to $40 \%$ indicated with light red, less than $10 \%$ infected rates indicated without color

into BL21 E. coli (DE3 strain) cells. The expression of the His-tagged fusion proteins rRAP-1a61-1 and rRAP-1a61$1 / \mathrm{CT}$ was induced in the presence of kanamycin $(50 \mu \mathrm{g} /$ $\mathrm{ml}$ ) by adding $1 \mathrm{mM}$ IPTG and then culturing the cells at $15{ }^{\circ} \mathrm{C}$ for $16 \mathrm{~h}$. The bacterial cultures were harvested and lysed using ultrasonication in binding buffer (50 mM Tris, $6 \mathrm{M} \mathrm{Gu}-\mathrm{HCl} ; \mathrm{pH}$ 8.0) containing phenylmethylsulfonyl fluoride (PMSF) and then purified as inclusion bodies from the E. coli cells. The target protein was then eluted using urea followed by a series of buffers containing increasing concentrations of imidazole $(200 \mathrm{mM}, 500 \mathrm{~m} \mathrm{mM}$ and $2500 \mathrm{~m} \mathrm{mM}$ ). After the proteins were renatured, they were suspended in $1 \times$ SDS-PAGE sample loading buffer (62.5 mM Tris- $\mathrm{HCl}$ [pH 6.8], $2 \%$ SDS, $5 \%$ mercaptoethanol, $10 \%$ glycerol, and $0.02 \%$ bromophenol blue) and boiled for $5 \mathrm{~min}$. The samples were briefly centrifuged prior to being separated using SDS-PAGE. Recombinant protein expression was then analyzed using Western blot analysis.

Preparation of anti-rRAP-1/CT specific rabbit immune serum New Zealand Rabbits (2 kg each) were subcutaneously injected with $400 \mu \mathrm{g}$ of purified rRAP-1a61-1/CT protein that had been emulsified in Freund's complete adjuvant (FCA, Sigma). In the negative control, the sera were collected from each rabbit prior to the first injections. Booster injections contained the same amount of protein in Freund's incomplete adjuvant (FIA, Sigma). These injections were administered on days 15, 20 and 28. The sera were collected from the immunized rabbits 15 days after the last injection, purified and stored at $-20{ }^{\circ} \mathrm{C}$ until further use.

\section{Western blot analysis}

Approximately $20 \mu \mathrm{g}$ of purified Babesia sp. BQ1 (Lintan) recombinant proteins (rRAP-1a61-1 and rRAP-1a61-1/ CT) were separated using SDS-PAGE in $18 \%$ polyacrylamide gels. The proteins were transferred to nitrocellulose (NC) membranes with a $0.45 \mu \mathrm{m}$ pore size (BioRad) at $24 \mathrm{~V}$ and $50 \mathrm{~W}$ for $35 \mathrm{~min}$. The membrane was then cut into $0.25 \mathrm{~cm}$ strips and incubated in a blocking solution [5 \% skimmed milk powder in Tris-buffered saline (pH 7.6) with $0.1 \%$ Tween-20 (TBST)] for approximately $3 \mathrm{~h}$ at $4{ }^{\circ} \mathrm{C}$ on a shaker. After the NC strips had been washed three times, they were incubated for $1 \mathrm{~h}$ with each tested serum (diluted at 1:100 in TBST). After the strips were washed three times in TBST, they were incubated for $2 \mathrm{~h}$ with monoclonal anti-goat/sheep IgG-alkaline phosphatase conjugates (Sigma, A8062, dilution: 1:5000). The strips were then washed three times with TBST and incubated in a 5-bromo-4-chloro-3-indolyl phosphate/ nitro blue tetrazolium (BCIP/NBT) liquid substrate system (B1911-100ML, Sigma) for 15 to $20 \mathrm{~min}$. The approximate molecular weights of the revealed proteins 
were evaluated by comparing their migration to a standard molecular weight marker (SM0671, 10-170 kDa, PageRuler Prestained Protein Ladder; SM1861, 1.7-40 kDa, Spectra Multicolor Low Range Protein Ladder, Thermo Scientific).

\section{IFAT and confocal laser microscopic observation}

An immunofluorescence analysis was performed using a procedure previously described by Moitra et al. [39] with rabbit antiserum directed against rRAP-1a61-1/CT. The iRBC membrane was stained using a PKH26 red fluorescent cell membrane labeling kit (MINI26, Sigma-Aldrich) according to the manufacturer's instructions. The iRBCs were fixed in a buffer containing $4 \%$ paraformaldehyde and $10 \mathrm{mM}$ piperazine- $\mathrm{N}, \mathrm{N}$-bis (2-ethanesulfonic acid) in PBS (PIPES) at pH 6.4 on $22 \mathrm{~mm}^{2}$ poly-L-lysine-coated coverslips for $30 \mathrm{~min}$ at room temperature. The coverslips were washed in PBS and then blocked for $1 \mathrm{~h}$ in $3 \%$ bovine serum albumin (BSA) in PBS containing $0.25 \%$ Triton X-100. The coverslips were stained overnight at $4{ }^{\circ} \mathrm{C}$ with either pre-immune serum or purified anti-rRAP1a61-1/CT serum (1:50) diluted in blocking buffer without Triton X-100. The coverslips were washed 3 times in PBS, stained for $1 \mathrm{~h}$ with FITC-conjugated anti-rabbit IgG (whole molecule) secondary antibodies (Sigma: F0382; $1: 80$ ), and then washed 3 times in PBS. The coverslips were stained with $1 \mu \mathrm{g} / \mathrm{ml} \mathrm{4,6-diamidino-2-phenylindole} \mathrm{(DAPI)}$ (Sigma: D8417) for $10 \mathrm{~min}$ and then examined for reactivity using confocal microscopy.

\section{ELISA}

The optimum concentration of coating buffer $(0.1 \mathrm{M}$ carbonate/bicarbonate, $\mathrm{pH}$ 9.6) was determined for rRAP1a61-1/CT (100 $\mu \mathrm{l} \mathrm{at} 2 \mu \mathrm{g} / \mathrm{ml})$. It was then distributed and adsorbed in 96-well flat-bottom microplates at $4{ }^{\circ} \mathrm{C}$ overnight. After three washes with PBST (0.1\% Tween-20), the plates were blocked with $200 \mu \mathrm{l}$ of $2 \%$ gelatin in PBST at $37{ }^{\circ} \mathrm{C}$ for $1 \mathrm{~h}$. After the plates were washed, the positive and negative sera (dilution: 1/100) were distributed in duplicate, and the plates were incubated for $1 \mathrm{~h}$ at $37^{\circ} \mathrm{C}$. After the plates were washed 3 times, $100 \mu \mathrm{l}$ of monoclonal antigoat/sheep IgG-peroxidase (Sigma, A9452, dilution: 1:1000) was added to each well, and the wells were incubated for $1 \mathrm{~h}$ at $37^{\circ} \mathrm{C}$. After the plates were washed another 3 times, $100 \mu \mathrm{l}$ of 1 -Step ${ }^{\mathrm{Tm}}$ Ultra TMB-ELISA $(34028-250 \mathrm{ml}$, Thermo Scientific) was added to each well, and the plates were incubated for 15 to $25 \mathrm{~min}$ at room temperature. The reaction was stopped by adding $100 \mu \mathrm{l}$ of $2 \mathrm{M} \mathrm{H}_{2} \mathrm{SO}_{4}$, and the plates were read at $450 \mathrm{~nm}$ using an ELISA automat (Bio-Rad Model 680 microplate reader, USA).

\section{Statistical analysis}

The $95 \%$ confidence intervals (95\% CIs) for the overall prevalence values of Babesia sp. BQ1 (Lintan) infection were calculated using IBM SPSS Statistics version 19.0.

\section{Results}

Cloning and expression of RAP-1a61-1 and C-terminaltruncated RAP-1a61-1

The genes encoding RAP-1a61-1 (aa 22-474) and Cterminal RAP-1a61-1/CT (aa 325-474) (aa sequence corresponding to GenBank accession number AGV15809) were successfully amplified using PCR and inserted into the cloning vector pUC57. The pET-30a-RAP-1a61-1 and pET-30a-RAP-1a61-1/CT recombinant plasmids were identified using enzyme restriction analysis (Sac I/Sal I and Mlu I/Hind III, respectively) and confirmed by sequencing using specific primers. The insert sequences were also verified (data not shown). After the expression of each recombinant protein was induced using IPTG, the E. coli lysates were analyzed using SDS-PAGE and Western blot analysis of an anti-His serum. The results of SDS-PAGE showed that rRAP-1a61-1 and rRAP-1a61-1/ CT were expressed as proteins that were approximately $52 \mathrm{kDa}$ and $20 \mathrm{kDa}$ in size, respectively (Fig. 2).

\section{Evaluation of the specificity of rRAP-1a61-1 and rRAP-1a61-1/CT using Western blot analysis}

The reactivity of each positive serum that was obtained from infected sheep with rRAP-1a61-1 and rRAP-1a61$1 / \mathrm{CT}$ was analyzed using Western blot analysis. Strong reactions showing an expected size of rRAP-1a61-1/CT (approximately $20 \mathrm{kDa}$ ) were observed in the positive sera obtained from sheep infected with Babesia sp. BQ1 (Lintan) (No. 3216), Babesia sp. BQ1 (Ningxian) (No. 08026) and Babesia sp. Tianzhu (No. 08040). In contrast, no reaction was observed between rRAP-1a61-1/ $\mathrm{CT}$ and sera obtained from sheep infected with Babesia sp. Hebei (No. 08020) and Babesia sp. Xinjiang (No. 3201) (Fig. 3). Furthermore, cross-reactivity between the full-length rRAP-1a61-1 protein and sera from Babesia sp. Xinjiang-infected sheep and B. bigemina-infected cattle was also observed (data not shown).

\section{Identification of native RAP-1 proteins using Western blot analysis and IFAT}

To identify native RAP-1 in Babesia sp. BQ1 (Lintan) merozoites, antibodies against the $\mathrm{C}$-terminal-truncated recombinant RAP-1a61-1/CT were obtained from rabbits and the positive serum obtained from animals infected with Babesia sp. BQ1 (Lintan) (No. 3216), and the RAP-1a61-1 protein was detected at approximately $52 \mathrm{kDa}$ in the lysates of Babesia sp. BQ1 (Lintan)-infected sheep erythrocytes (Fig. 4). No specific reaction was observed in Western blot analyses between the sera with the lysates of uninfected sheep erythrocytes (data not shown).

The IFAT results showed that the merozoite nucleus of parasites were stained with DAPI and FITC-conjugated anti-rabbit IgG is able to detect anti-rRAP-1a61-1/CT 


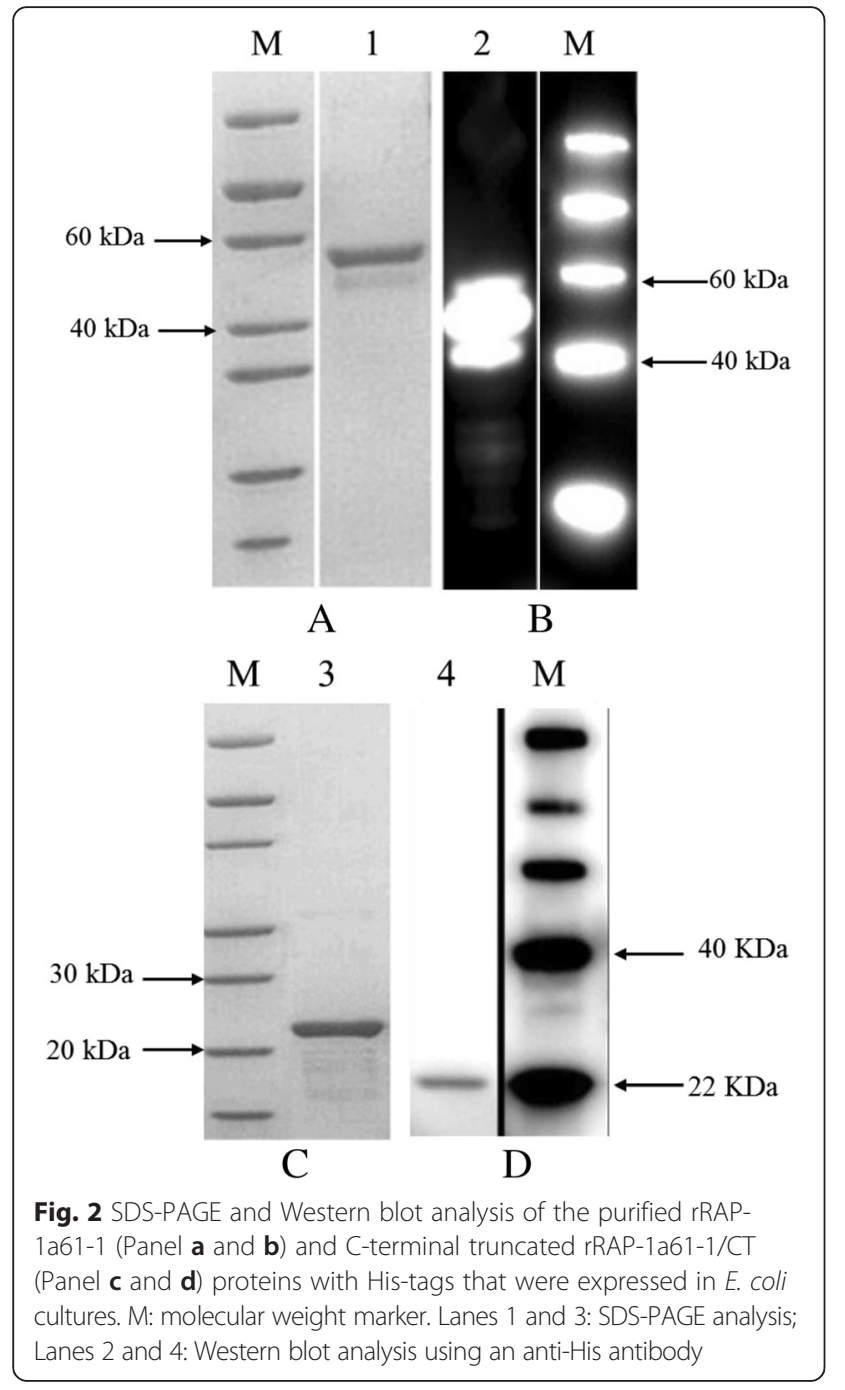

antiserum. The immunofluorescence signals are the result of the interaction between the serum from a rabbit that was immunized by rRAP-1a61-1/CT and Babesia sp. BQ1 (Lintan) merozoites. Specific fluorescent signaling was not detected using pre-immune rabbit serum (Fig. 5).
Cross-reactivity with other hemoparasites using ELISA Positive sera against Babesia sp. BQ1 (Lintan), Babesia sp. BQ1 (Ningxian), Babesia sp. Tianzhu, Babesia sp. Hebei, Babesia sp. Xinjiang, T. lunwenshuni, T. uilenbergi, A. ovis, B. bovis, and B. bigemina were tested using ELISA to evaluate cross-reactivity with rRAP-1a61-1/ $\mathrm{CT}$. The tests were repeated in triplicate, and the specific antibody mean rate $(A b R \%=($ Sample mean OD-Negative control mean OD)/(Positive control mean OD-Negative control mean OD) $\times 100)$ and standard deviation were calculated using Excel 2007 [38]. The results indicated that cross-reactivity was observed only between three B. motasi-like isolates (Lintan, Tianzhu and Ningxian) and that no cross-reactivity was observed with the sera against Babesia sp. Hebei, T. lunwenshuni, T. uilenbergi, B. bovis, B. bigemina or A. ovis (Fig. 6).

The kinetics of anti-Babesia sp. BQ1 (Lintan) antibodies were tested in experimentally infected sheep using ELISA The kinetics of antibodies produced against RAP-1a have been studied using ELISA with rRAP-1a61-1/CT in sera collected from 5 intact infected sheep (Nos. 3216, 2007, 3390, 3533 and 3446) before (0 weeks postinfection, WPI0) and after infection (from WPI1 to WPI12). A significant increase in the amount of antibodies produced against RAP-1a was observed after the sheep were infected, but varying kinetics were observed between individual sheep. In two of the Chinese sheep (Nos. 3216 and 2007), antibody production against RAP1a was increased during the early phase of infection, at 1-3 weeks (WPI1-3), after which it decreased. In contrast, a gradual increase in the number of antibodies produced against RAP-1a was observed in the three French sheep (Nos. 3390, 3533 and 3446). Higher antibody levels were observed at 6-7 weeks post-infection (WPI6-7) in sheep Nos. 3390 and 3446 and at 9 weeks (WPI9) in sheep No. 3533. In general, antibodies were produced at 1 week post-inoculation, continued to increase through 6 weeks (WPI6), and remained stable

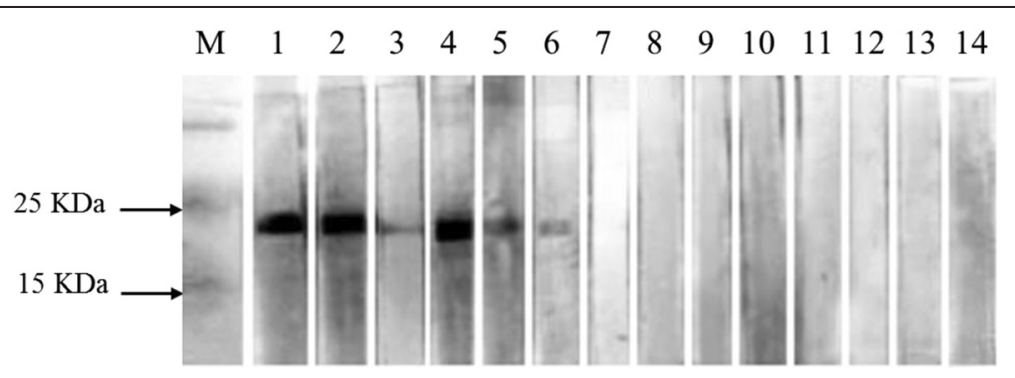

Fig. 3 Western blot analysis of the recombinant RAP-1a61-1/CT protein in Babesia sp. BQ1 (Lintan). M: molecular weight marker. Lanes 1 and 2: positive sera for Babesia sp. BQ1 (Lintan) (WPI3 and 4); Lanes 3 and 4: positive sera for Babesia sp. Tianzhu (WPI3 and 4); Lanes 5 and 6: positive sera for Babesia sp. BQ1 (Ningxian) (WPI3 and 4); Lanes 7 and 8: positive sera for Babesia sp. Hebei (WPI3 and 4); Lanes 9 and 10: positive sera for Babesia sp. Xinjiang (WPI3 and 4); Lanes 11-13: positive sera for B. bigemina, B. bovis and T. luwenshuni; and Lane 14: pre-immunized sheep (No. 3216) sera were used as the negative controls 


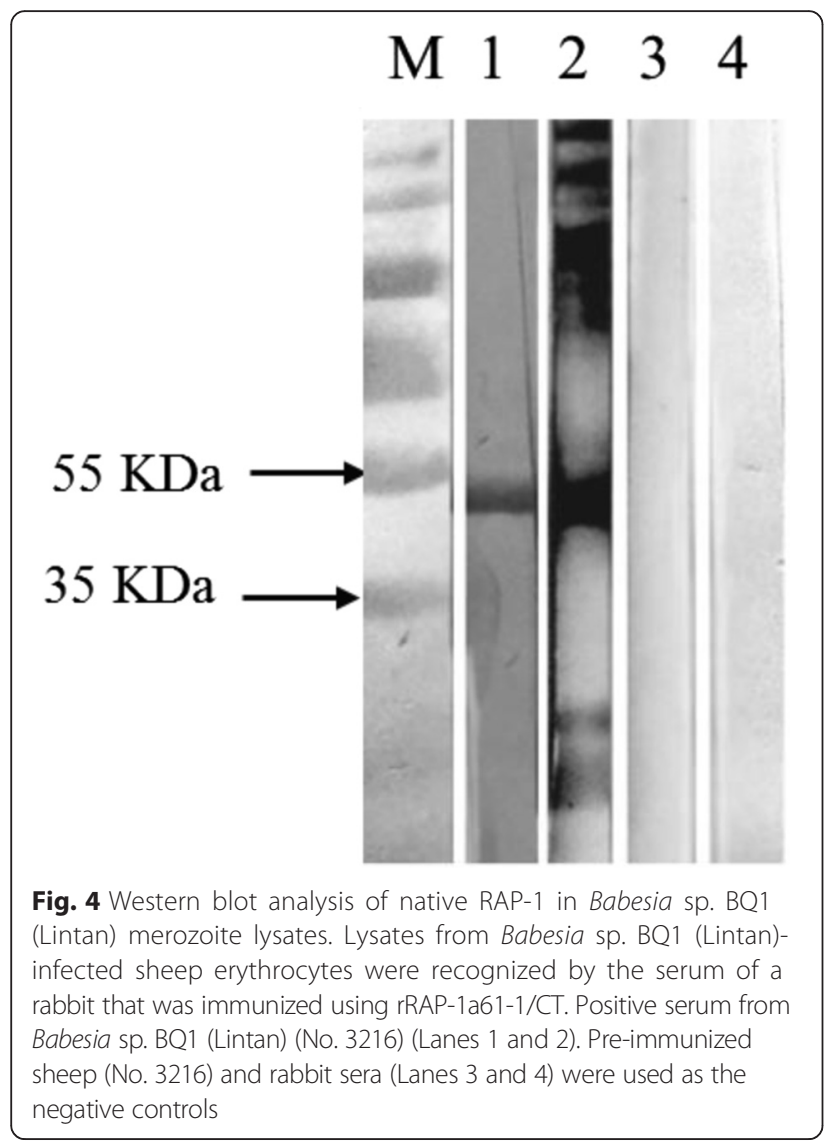

until 9 weeks (WPI9), after which slight decreases were observed through 12 weeks (WPI9-12). High levels of antibodies against RAP-1a usually lasted 3 months (84 days p.i.), despite the decrease in production that was observed after 6 weeks (42 days p.i.) (Fig. 7).

\section{Evaluation of specificity, sensitivity and positive threshold} values in ELISA to detect rRAP-1/CT

MedCalc statistical software was used to evaluate the sensitivity, specificity, and positive threshold value in ELISAs performed to test 191 positive sera and 492 negative sera, as previously described [40]. A percentage corresponding to the specific antibody mean rate (AbR \%) was calculated for each serum sample. The results indicated that the threshold value was $18.84 \%$, which corresponded to $94.8 \%$ sensitivity $(95 \% \mathrm{CI}=82.4-$ 98.4) and $96.1 \%$ specificity (95\% CI $=85.1-99.4)$. The numbers of false positive and false negative sera were 10 and 15, respectively (Fig. 8).

\section{ELISA identification of the rRAP-1a61-1/CT protein as a} potential antigen for use in serological epidemiology in B. motasi-like sub-group (Lintan, Ningxian and Tianzhu isolates) infections

Field serum samples were extracted from a total of 3198 sheep and goats from 54 different regions of 23 Chinese provinces. The samples were analyzed using ELISA to evaluate the prevalence of infection with $B$. motasi-like

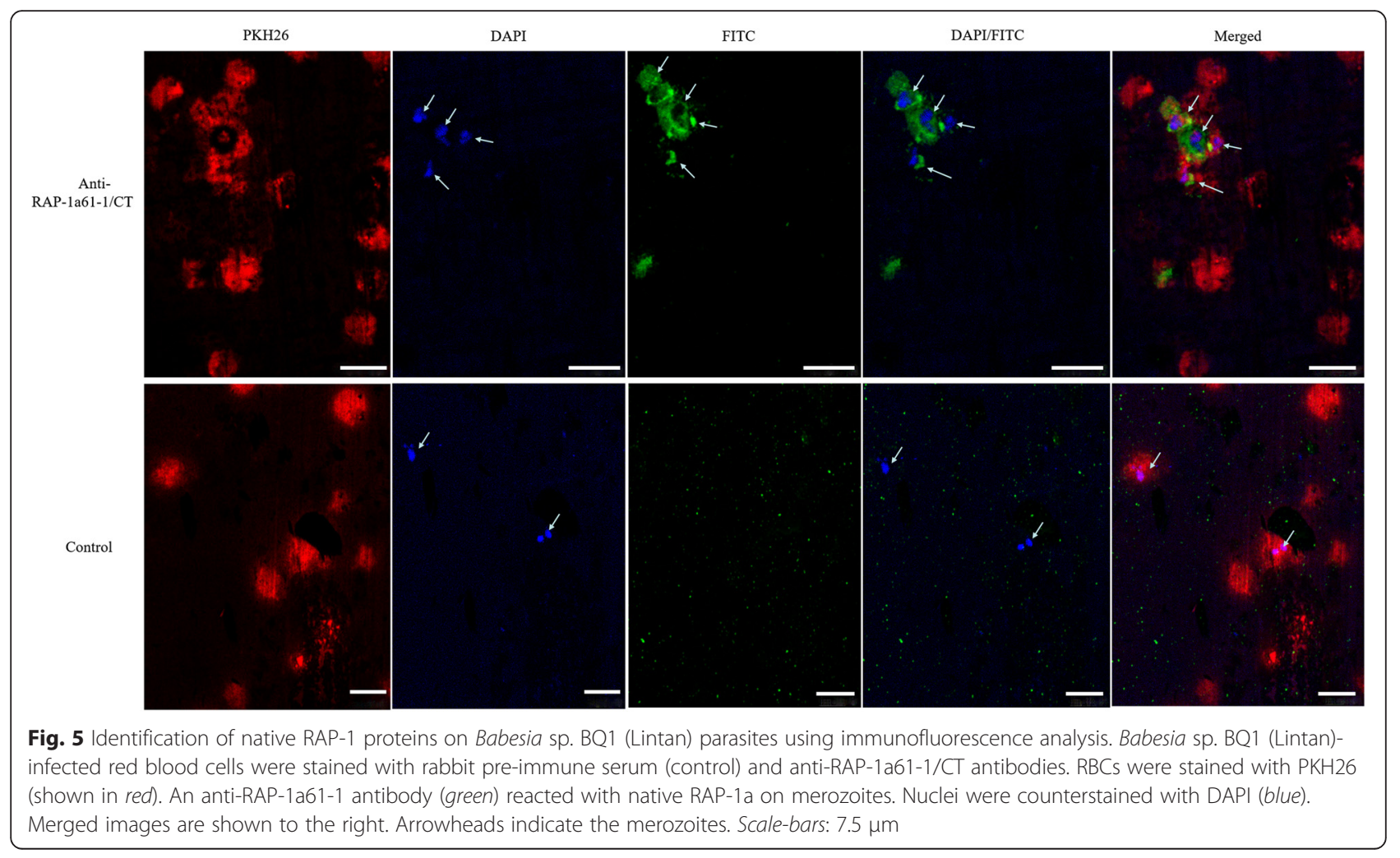




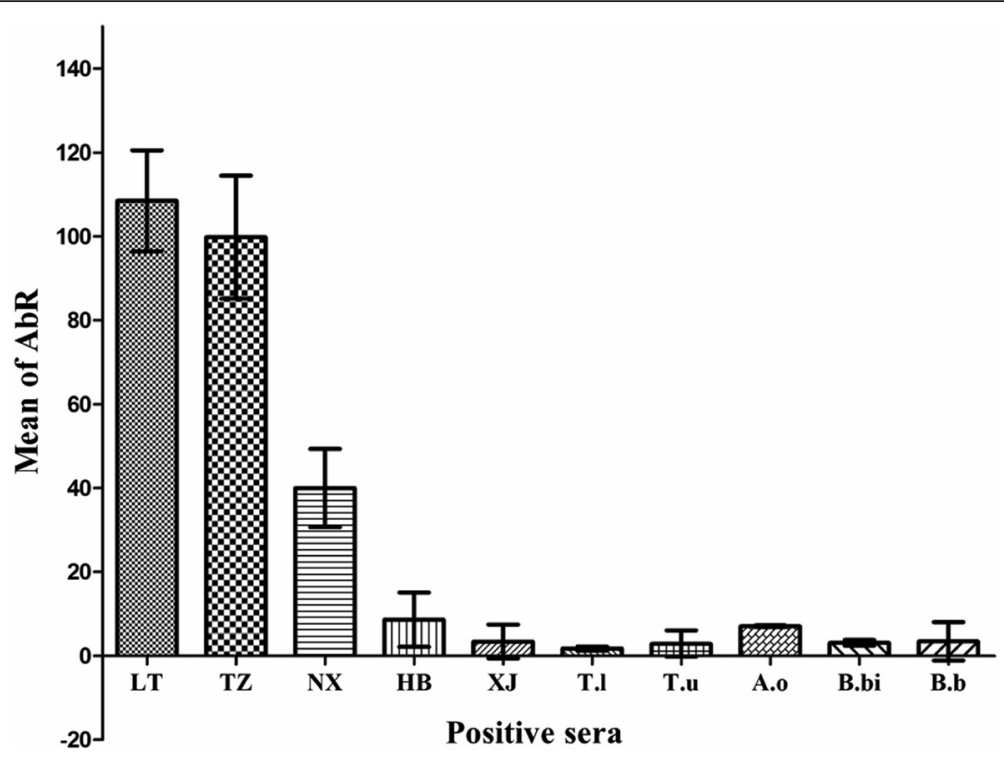

Fig. 6 The cross-reactivity of rRAP-1a61-1/CT from Babesia sp. BQ1 (Lintan) with positive sera against Babesia-, Theileria- and Anaplasma-infected sheep or cattle was determined using ELISA. LT: Babesia sp. BQ1 (Lintan), TZ: Babesia sp. Tianzhu, NX: Babesia sp. BQ1 (Ningxian), HB: Babesia sp. Hebei, XJ: Babesia sp. Xinjiang, T.I: T. luwenshuni, T.u: T. uilenbergi, A.o: A. ovis, B.bi: B. bigemina and B. bo: B. bovis

(Lintan, Ningxian and Tianzhu) isolates in these regions. The results of ELISA detection to identify positive samples are summarized in Table 1. Sero-positive with $B$. motasi-like were identified in 51 regions covering all 23 surveyed provinces. The total positive rate in these regions was $36.02 \%(95 \% \mathrm{CI}=33.7-68.4)$. The seroprevalence ranged from 2.22 to $81.11 \%$. The significantly high positive rates exceeded $50 \%$ in 7 of the 23 surveyed provinces, including Liaoning (50\%), Inner Mongolia (61.01 \%), Shaanxi (75.68 \%), Hunan (52.73\%), Sichuan (59.72\%), Anhui (81.11\%) and Shanxi (58 \%). Three additional provinces, including Qinghai (45.35\%), Ningxia (49.38 \%) and Guangdong (41.89\%), had positive rates exceeding $40 \%$. Lower sero-prevalence was observed in Tibet (2.22\%), Jilin (7.55 \%) and Guangxi provinces $(9.74 \%)$. Positive rates that were greater than $80 \%$ were observed in Chifeng (86.15\%) in Inner Mongolia and Lintan $(83.33 \%)$ in the Gansu provinces (Table 1, Fig. 1).

\section{Discussion}

In the genus Babesia, RAP-1 was initially described according to its recognition by monoclonal antibodies to merozoite antigens in B. bigemina. It was designated p58 at that time [41], and it was subsequently identified in all Babesia species that were examined. The sequence of the full-length rap-1 gene was first published in B. bovis (named pBv60) [18], and the sequence and multigene nature of p58 (later named rap-1a) were described in $B$.

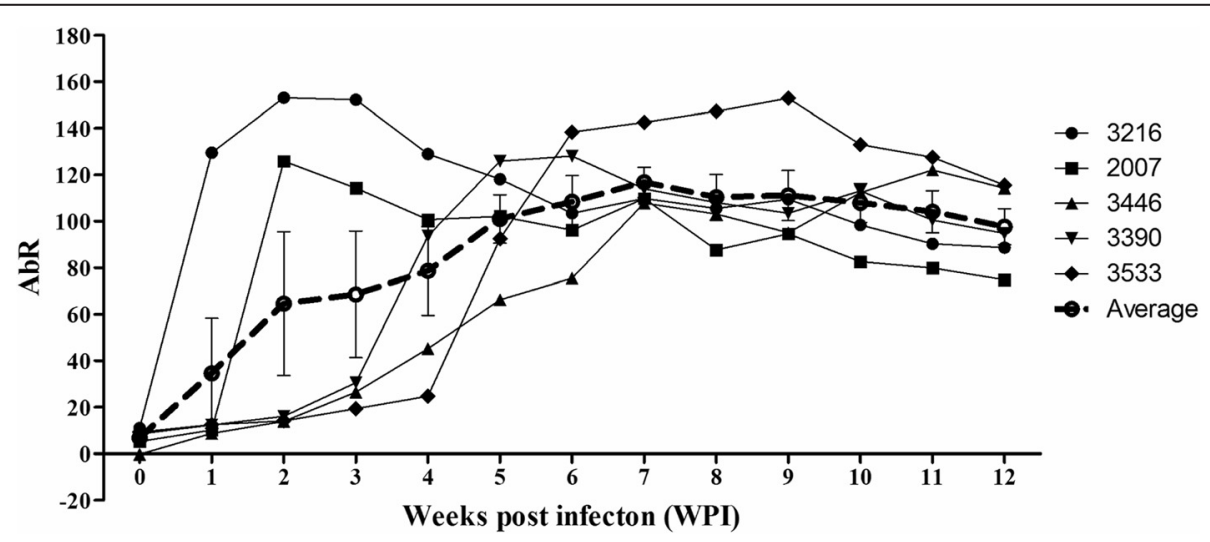

Fig. 7 Kinetics of anti-Babesia sp. BQ1 (Lintan) antibodies in 5 sheep (Nos. 3216, 2007, 3446, 3390 and 3533) that were experimentally infected. The error bars indicate the standard deviations, and the bold dotted line shows the mean AbR that corresponded to each time point 


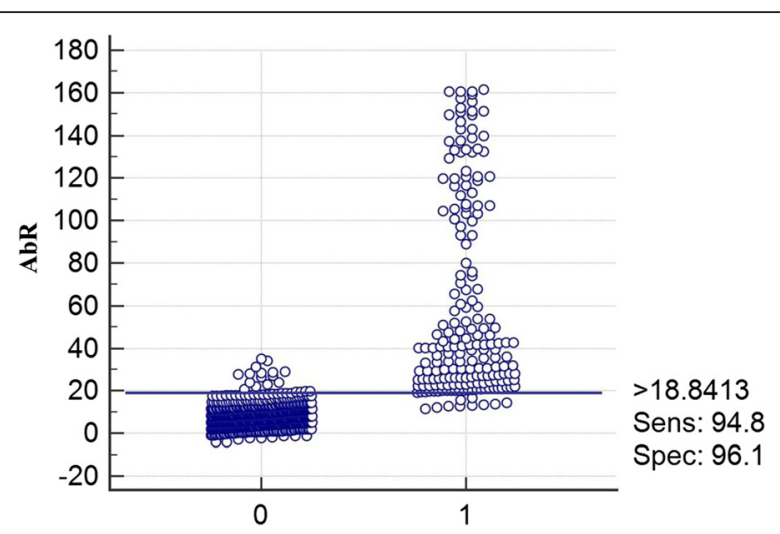

Fig. 8 Evaluation of the specificity, sensitivity and positive threshold value of rRAP-1/CT in ELISA using antibody mean rates (AbRs) for positive and negative sera. $0=$ negative sera, and $1=$ positive sera

bigemina [42]. The name RAP-1 was first applied when $B$. bovis pBv60 was found to be localized in rhoptries under immunoelectron microscopy [27]. The definitive structure of the rap-1 locus was initially defined in B. bovis [43] and then in B. bigemina [44]. In summary, an antibody reacting with a B. bigemina protein (p58) that was later identified as rap-1 was reported before its B. bovis homologue, and the sequence features, the association of these proteins with rhoptries, and the detailed organization of the locus containing rap-1 were initially described in B. bovis. In all studied Babesia species, the RAP-1 proteins share common conserved features that include the strict conservation of 4 cysteine residues, a highly conserved 14 amino acid motif and several shorter conserved oligopeptide motifs in the first $\mathrm{N}$-terminal 300 amino acids. Among babesial parasites, the $\mathrm{N}$-terminal regions of RAP-1 are more conserved than those in the C-terminal region [32, 35].

In bovine Babesia species, previous studies have indicated that the full-length recombinant RAP-1a in $B$. bovis could be used as a diagnostic antigen in ELISA to detect antibodies and to show cross- reactivity with B. bigemina because of the conserved features in the $\mathrm{N}$-terminus of RAP-1, as described above [29]. In contrast, RAP-1 B-cell epitopes in B. bovis and $B$. bigemina have been mapped using monoclonal antibodies and immune sera obtained from cattle, and the results demonstrated that the $\mathrm{B}$-cell epitopes primarily targeted the $\mathrm{C}$-terminal region of the proteins $[27,45,46]$. Moreover, an ELISA based on recombinant RAP-1a that is modified in the C-terminal region has been developed to improve its sensitivity and specificity for antibody detection and could be widely used as an antigen for serodiagnosis and epidemiological survey purposes [37, 47-50]. In B. motasi-like isolates, software prediction of RAP-1a B-cell epitopes demonstrated that B-cell epitopes were also located in the C-terminal region. Only a few B cell-epitopes were predicted in the $\mathrm{N}$-terminal region (data not shown). Interestingly, the amino acid sequences between RAP-1a61 and RAP-1a67 are more conserved at the $\mathrm{C}$-terminal region than the $\mathrm{N}$-terminal region in B. motasi-like [34], which is not consistent with the common features described above. Moreover, the sequences of RAP-1a and the full rap-1 locus, including the intergenic regions in three isolates (Lintan, Ningxian and Tianzhu) of B. motasi-like, were almost identical [12]. The features of the more conserved Cterminal region of the RAP-1a protein in B. motasilike could indicate that this form is an ideal candidate for diagnostics aimed at identifying several B. motasilike isolates.

The sera were able to recognize the native RAP-1 protein in Western blot analysis and IFAT, suggesting that the sheep had been immunized against RAP-1 during infection. Significant cross-reactivity was observed between rRAP-1a61-1/CT of Babesia sp. BQ1 (Lintan) and the positive sera obtained from Babesia sp. Tianzhu and Babesia sp. BQ1 (Ningxian) in both Western blot analyses and ELISA, but not in the Hebei isolate. This is not surprising because the rap-1a sequences were almost identical in these three Babesia isolates at both the nucleotide and amino acid level. In contrast, the sequences of all of the rap-1 genes obtained from Babesia sp. Hebei were clearly different from the other 3 isolates, suggesting that this isolate might belong to a different species [12]. These findings were inconsistent with a previous study that indicated that weak cross-reactivity between Babesia sp. BQ1 (Ningxian) and Babesia sp. BQ1 (Lintan) was detected using Western blot analysis but not ELISA using a merozoite antigen (BQMA) [40]. Some novel antigens (e.g., BQP35 and BQHsp90) for Babesia sp. BQ1 (Lintan) were recently identified as candidate diagnostic antigens. Western blot analysis and ELISA tests that are based on BQP35 have shown that there is cross-reactivity between Babesia sp. BQ1 (Lintan) and Babesia sp. Tianzhu, which is in agreement with the results obtained when merozoite extracts were used [51]. However, rBQHSP90 could not differentiate between any B. motasi-like isolates and Babesia sp. Xinjiang, another distinct ovine Babesia species [52]. Differences in crossreactivity have been observed when using the ELISA method based on BQP35, BQHsp90 or RAP-1a of Babesia sp. BQ1 (Lintan), and these might be caused by differences in molecular characterizations and the detection limitations and sensitivities of these antigens. These findings suggest that rRAP-1a61-1/CT could be used as a potentially diagnostic antigen to increase the sensitivity and specificity of such tests, and that it might replace native crude parasite antigens, which require parasite reproduction (from the killing of experimentally infected animals) or the in vitro harvesting of cultures $[53,54]$. 
Table 1 Prevalence of Babesia sp. BQ1 Lintan in field samples collected from 23 provinces by detected antibodies produced from rRAP-1a CT with ELISA

\begin{tabular}{|c|c|c|c|c|c|}
\hline Province & Prefecture & No. of sera & No. of positive sera & $\begin{array}{l}\text { Positive rate (\%) in different } \\
\text { regions }\end{array}$ & $\begin{array}{l}\text { Positive rate (\%) in each } \\
\text { province }\end{array}$ \\
\hline Qinghai & Haibei & 269 & 122 & & (122/269) 45.35 \\
\hline \multirow[t]{3}{*}{ Xinjiang } & Yili & 229 & 82 & 35.81 & (118/419) 28.16 \\
\hline & Akesu & 90 & 20 & 22.22 & \\
\hline & Habahe & 100 & 16 & 16 & \\
\hline \multirow[t]{5}{*}{ Gansu } & Jingtai & 120 & 8 & 6.67 & (160/447) 35.79 \\
\hline & Jiayuguan & 81 & 6 & 7.41 & \\
\hline & Tianzhu & 81 & 56 & 69.14 & \\
\hline & Yongchang & 75 & 15 & 20 & \\
\hline & Lintan & 90 & 75 & 83.33 & \\
\hline Tibet & Lhasa & 90 & 2 & & (2/90) 2.22 \\
\hline \multirow[t]{3}{*}{ Liaoning } & Huanren & 29 & 14 & 48.28 & (42/84) 50 \\
\hline & Anshan & 27 & 10 & 37.04 & \\
\hline & Fengcheng & 28 & 18 & 64.29 & \\
\hline \multirow[t]{2}{*}{ Jilin } & Yongji & 26 & 3 & 11.54 & (4/53) 7.55 \\
\hline & Jiutai & 27 & 1 & 3.70 & \\
\hline \multirow[t]{4}{*}{ Inner Mongolia } & Ordos & 63 & 21 & 33.33 & (133/218) 61.01 \\
\hline & Manzhouli & 13 & 0 & 0 & \\
\hline & Baotou & 12 & 0 & 0 & \\
\hline & Chifeng & 130 & 112 & 86.15 & \\
\hline Shaanxi & Yulin & 74 & 56 & & (56/74) 75.68 \\
\hline Ningxia & Wuzhong & 81 & 40 & & (40/81) 49.38 \\
\hline \multirow[t]{4}{*}{ Guangxi } & Jingxi & 35 & 3 & 8.57 & (15/154) 9.74 \\
\hline & Tianyang & 56 & 10 & 17.85 & \\
\hline & Pingxiang & 18 & 0 & 0 & \\
\hline & Guilin & 45 & 2 & 4.44 & \\
\hline \multirow[t]{2}{*}{ Hunan } & Xinhuang & 29 & 16 & 55.17 & (29/55) 52.73 \\
\hline & Xiangtan & 26 & 13 & 50 & \\
\hline \multirow[t]{2}{*}{ Sichuan } & Panzhihua & 36 & 25 & 69.44 & (43/72) 59.72 \\
\hline & Hejiang & 36 & 18 & 50 & \\
\hline \multirow[t]{7}{*}{ Yunnan } & Fuyuan & 35 & 2 & 5.71 & $(65 / 202) 32.18$ \\
\hline & Honghe & 32 & 16 & 50 & \\
\hline & Jinghong & 20 & 5 & 25 & \\
\hline & Yanshan & 34 & 10 & 29.41 & \\
\hline & Menghai & 12 & 3 & 25 & \\
\hline & Ruili & 32 & 14 & 43.75 & \\
\hline & Kunming & 37 & 15 & 40.54 & \\
\hline Anhui & Hefei & 90 & 73 & & (73/90) 81.11 \\
\hline \multirow[t]{2}{*}{ Guangdong } & Zhaoqing & 38 & 20 & 52.63 & (31/74) 41.89 \\
\hline & Lianzhou & 36 & 11 & 30.56 & \\
\hline \multirow[t]{4}{*}{ Guizhou } & Dushan & 30 & 1 & 3.33 & (46/166) 27.71 \\
\hline & Ziyun & 32 & 13 & 40.63 & \\
\hline & Yuping & 32 & 19 & 59.38 & \\
\hline & Guiyang & 72 & 13 & 18.06 & \\
\hline
\end{tabular}


Table 1 Prevalence of Babesia sp. BQ1 Lintan in field samples collected from 23 provinces by detected antibodies produced from rRAP-1a CT with ELISA (Continued)

\begin{tabular}{|c|c|c|c|c|c|}
\hline Province & Prefecture & No. of sera & No. of positive sera & $\begin{array}{l}\text { Positive rate (\%) in different } \\
\text { regions }\end{array}$ & $\begin{array}{l}\text { Positive rate (\%) in each } \\
\text { province }\end{array}$ \\
\hline \multirow[t]{2}{*}{ Chongqing } & Jiangjin & 30 & 11 & 36.67 & $(15 / 53) 28.30$ \\
\hline & Wanzhou & 23 & 4 & 17.39 & \\
\hline Shandong & Dongying & 90 & 19 & & (19/90) 21.11 \\
\hline Shanxi & Lvliang & 50 & 29 & & (29/50) 58 \\
\hline \multirow[t]{3}{*}{ Zhejiang } & Jingning & 36 & 15 & 41.67 & (32/117) 27.35 \\
\hline & Qingtian & 29 & 4 & 13.79 & \\
\hline & Hangzhou & 52 & 13 & 25 & \\
\hline Hubei & Suizhou & 81 & 27 & & (27/81) 33.33 \\
\hline Hebei & Baoding & 169 & 25 & & (25/169) 14.79 \\
\hline \multirow[t]{2}{*}{ Henan } & Linzhou & 60 & 20 & 33.33 & $(26 / 90) 28.89$ \\
\hline & Neihuang & 30 & 6 & 20 & \\
\hline Total & & 3198 & 1152 & & (1152/3198) 36.02 \\
\hline
\end{tabular}

The kinetics analysis revealed that the humoral immune response to this parasite varied in different sheep breeds (Chinese and French sheep) during the course of infection. This result was inconsistent with a previous study that used BQMA and indicated that there is no difference in kinetics between these two sheep breeds [38]. Antibody production against RAP-1 was initially increased in the two infected Chinese sheep between WPI1 and WPI2, but it then decreased. These results were consistent with the findings of a recent study, in which a RAP-1a peptide designed from the RAP-1a Nterminal of Babesia sp. BQ1 (Lintan) was used as an antigen to perform ELISA. Antibody production against this peptide displayed kinetics that were similar to those observed against rRAP-1a61-1 (data not shown). In contrast, the production of specific antibodies against Babesia sp. BQ1 (Lintan) in the three infected French sheep was increased at three weeks post-infection and peaked between six and nine weeks post-infection. On average, RAP-1a was expressed at sequentially higher levels from week 1 to week 7 post-infection before its levels subsequently decreased. The difference in the kinetics of antibody production between these five infected sheep might result from differences in sheep breeds or individual variation. In general, our results are similar to those described in a previous study that used a merozoite antigen (BQMA) to evaluate the kinetics of antibody production during the course of Babesia sp. BQ1 (Lintan) infection. That study showed that antibody production was decreased from WPI 12 (approximately 80 DPI) [38].

A serological diagnostic test (ELISA) is the most practical and economical assay for a wide range of epidemiological investigative purposes, and it has been established as a method for evaluating the lysates of Babesia-infected erythrocytes in a number of Babesia species [55]. However, studies focusing on the development of a serological diagnostic ELISA test that is based on recombinant immune antigens that can detect ovine babesiosis are rare. The development of ELISA tests requires preliminary knowledge of parasite polymorphism, the ability to successfully culture cells in vitro to produce antigens, and/or prior genetic knowledge of the targeted antigen so that specific sequences can be selected as an epitope. Some improved ELISA methods for sero-epidemiological surveys have been developed based on specific recombinant proteins (RAP-1 and SBPs) that are involved in the RBC invasion process in B. bovis, B. bigemina and B. caballi species $[36,37,50,56]$. In this study, the results of seroinvestigations using an ELISA method that was developed based on the rRAP-1a61-1/CT protein indicated that Babesia sp. BQ1 (Lintan), Babesia sp. BQ1 (Ningxian) and Babesia sp. Tianzhu infections were identified in all of the investigated provinces. Recent large-scale seroepidemiological ELISA surveys of Babesia sp. BQ1 (Lintan) were performed in small ruminants from 22 provinces of China, and these were also regions that were tested in our study, and the results indicated that infection by this isolate was identified in all 22 investigated provinces, with an average prevalence of $43.5 \%$. These values are slightly higher than the values produced in our study and they showed a positive rate that was as high as $91 \%$ in Inner Mongolia [57]. The positive rates from 8 provinces that were tested using rRAP-1a were slightly higher, whereas the positive rates from 14 of the provinces were significantly lower in our study than in a previous study [57]. This variation may result from differences in the limitations of the tested antigens. Moreover, another 
sero-epidemiological investigation performed using ELISA to detect infections in small ruminants by Babesia species indicated that there was an average infection rate of $82.38 \%$ for Babesia sp. BQ1 (Lintan) in 261 sera samples obtained from Lintan County in Gansu province, and these result were similar to our results $(83.33 \%)$ for this region [38].

The positive rates from 10 of the 23 provinces were comparable to those found in a recent molecular detection study that used a nested PCR assay based on the rap$1 b$ gene of $B$. motasi-like species, the positive rates for Babesia sp. BQ1 (Lintan), Babesia sp. BQ1 (Ningxian) and Babesia sp. Tianzhu were 5, 13.8 and $21.9 \%$ in Inner Mongolia, Gansu and Xinjiang, respectively in this previous study (they were $61.01,35.79$ and $28.16 \%$, respectively, in our study) [58]. No B. motasi-like infections were detected in DNA samples obtained from the Zhejiang, Guizhou, Chongqing and Liaoning provinces when the nested PCR test was used [58]. Larger variation was observed in the numbers of positive samples that were identified in these provinces when ELISA was used in our study. A similar study was performed that compared the results of using ELISA (66.84 \%) and the molecular LAMP method (14.3\%) to analyze Babesia sp. BQ1 (Lintan) infections in Gansu province [38]. Therefore, the difference in prevalence that is observed when using different testing methods (e.g., PCR vs ELISA or LAMP vs ELISA) or different antigens (e.g., BQMA vs rRAP-1a) or when using the same method (e.g., ELISA) can be potentially explained by the parameters that were used or the limitations of the detection methods used in these assays.

Some studies have indicated that Haemaphysalis qinghaiensis and $H$. longicornis are the vectors of the Babesia sp. BQ1 (Lintan) isolate, while H. longicornis has been proposed as the transmission vector for Babesia sp. BQ1 (Ningxian). These two tick species are widely distributed in at least 20 provinces of China (Fig. 1) $[4,59,60]$. Whereas, the higher positive rates (exceed $25 \%$ ) of B. motasi-like were found in Inner Mongolia, Xinjiang, Hunan, Zhejiang, Guangdong and Chongqing, as well as in Guangxi with positive rate of $9.74 \%$ where the $H$. longicornis and $H$. qinghaiensis have not been reported yet. This has been explained by several possibilities by Wang et al. [57]. Moreover, cases of ovine babesiosis have been reported in many Chinese provinces, including Inner Mongolia, Henan, Shaanxi, Yunnan, Sichuan, Heilongjiang and Qinghai province [61-63]. Taken together, the results show that the wide prevalence of the $B$. motasi-like isolates (Lintan, Ningxian and Tianzhu) included in this study and co-infections between these three isolates is not surprising, and these isolates co-circulate in China with high prevalence. The results suggest that the development of ELISA methods that are based on the rRAP-1a61-1/CT described in our study indicate that this ELISA is a potential diagnostic method for epidemiological investigations of known related isolates in addition to other unidentified isolates in sheep B. motasi-like infections.

\section{Conclusions}

The present study demonstrates that antibodies against rRAP-1a61-1 can detect native RAP-1 in Babesia sp. BQ1 (Lintan) merozoite lysates in Western blot analysis and IFAT. The high conservation of RAP-1a across the three isolates from $B$. motasi-like parasites suggests that rRAP-1a61-1/CT could be a promising common diagnostic antigen that can detect geographically distinct isolates of $B$. motasi-like infections in sheep.

\section{Acknowledgements \\ This study was financially supported by the NSFC (Nos. 31502054, 31372432, 31201899, 31272556, 31402189, and 31471967), ASTIP, Creative Research Groups of Gansu Province (No. 1210RJIA006), NBCIS CARS-38, the Special Fund for Agro-scientific Research in Public Research (Nos. 201303035 and 201303037), MOA, the 973 Program (2015CB150300), Supporting Program (2013BAD12B03, 2013BAD12B05), MOST (China), and the Jiangsu Co-innovation Center Programme for the Prevention and Control of Important Animal Infectious Diseases and Zoonoses as a State Key Laboratory of Veterinary Etiological Biology Project.}

\section{Authors' contributions}

QN, JY, PY, YP and BZ performed the experiments, including cloning, expression, Western blot analysis, ELISA and IFAT. QN drafted the manuscript. ZL, EM, JL, GG and HY supervised all work. All authors read and approved the final version of the manuscript.

\section{Competing interests}

The authors declare that they have no competing interests.

\section{Author details}

${ }^{1}$ State Key Laboratory of Veterinary Etiological Biology, Key Laboratory of Veterinary Parasitology of Gansu Province, Lanzhou Veterinary Research Institute, Chinese Academy of Agricultural Science, Xujiaping 1, Lanzhou, Gansu 730046, P. R. China. ${ }^{2}$ Jiangsu Co-innovation Center for Prevention and Control of Important Animal Infectious Diseases and Zoonoses, Yangzhou 225009, P. R. China. ${ }^{3}$ INRA, UMR1300 Biology, Epidemiology and Risk Analysis in Animal Health, BP 40706F-44307 Nantes, France.

Received: 2 March 2016 Accepted: 5 May 2016

Published online: 31 May 2016

\section{References}

1. Friedhoff KT. Tick-borne diseases of sheep and goats caused by Babesia, Theileria or Anaplasma spp. Parassitologia. 1997;39:99-109.

2. Guan GQ, Yin H, Luo JX, Lu WS, Zhang QC, Ma ML, et al. Isolation of a large ovine Babesia sp. in Xinjiang, China. Chin J Vet Sci Technol. 2001;31:35-36 (In Chinese).

3. Guan GQ, Yin H, Luo JX, Lu WS, Zhang QC, Gao YL, et al. Transmission of Babesia sp. to sheep with field-collected Haemaphysalis qinghaiensis. Parasitol Res. 2002;88:S22-24.

4. Bai Q, Liu GY, Liu DK, Ren JX, Li X. Isolation and preliminary characterization of a large Babesia sp. from sheep and goats in the eastern part of Gansu Province, China. Parasitol Res. 2002;88:S16-21.

5. Uilenberg G. Babesia-A historical overview. Vet Parasitol. 2006;138:3-10.

6. Liu AH, Yin H, Guan GQ, Schnittger L, Liu ZJ, Ma ML, et al. At least two genetically distinct large Babesia species infective to sheep and goats in China. Vet Parasitol. 2007;147:246-51.

7. Niu QL, Luo JX, Guan GQ, Liu ZJ, Ma ML, Liu AH, et al. Differentiation of two ovine Babesia based on the ribosomal DNA internal transcribed spacer (ITS) sequences. Exp Parasitol. 2009;121:64-8. 
8. Gou H, Guan G, Ma M, Liu A, Liu Z, Ren Q, et al. Phylogenetic analysis based on $28 \mathrm{~S}$ rRNA of Babesia spp. in ruminants in China. Exp Appl Acarol. 2013; 59:463-72.

9. Tian ZC, Liu GY, Yin H, Luo JX, Guan GQ, Luo J, et al. RPS8-a new informative DNA marker for phylogeny of Babesia and Theileria parasites in China. PLoS One. 2013a;8:e79860.

10. Tian Z, Luo J, Zheng J, Xie J, Shen H, Yin H, et al. Phylogenetic analysis of Babesia species in China based on Cytochrome b (COB) gene. Infect Genet Evol. 2013b;13:36-40

11. Tian Z, Liu G, Yin H, Luo J, Guan G, Xie J, et al. Cytochrome c oxidase subunit III (COX3) gene, an informative marker for phylogenetic analysis and differentiation of Babesia species in China. Infect Genet Evol. 2013c;18:13-17.

12. Niu Q, Valentin C, Bonsergent C, Malandrin L. Strong conservation of rhoptry-associated-protein-1 (RAP-1) locus organization and sequence among Babesia isolates infecting sheep from China (Babesia motasi-like phylogenetic group). Infect Genet Evol. 2014;28:21-32.

13. Mosqueda J, Olvera-Ramirez A, Aguilar-Tipacamu G, Canto GJ. Current advances in detection and treatment of babesiosis. Curr Med Chem. 2012;19:1504-18.

14. Guerrero FD, Miller RJ, Pérez de León AA. Cattle tick vaccines: many candidate antigens, but will a commercially viable product emerge? Int J Parasitol. 2012:42:421-7.

15. Parizi LF, Reck Jr J, Oldiges DP, Guizzo MG, Seixas A, Logullo C, et al. Multi-antigenic vaccine against the cattle tick Rhipicephalus (Boophilus) microplus: a field evaluation. Vaccine. 2012;30:6912-7.

16. Gohil S, Herrmann S, Günther S, Cooke BM. Bovine babesiosis in the 21st century: Advances in biology and functional genomics. Int J Parasitol. 2013; 43:125-32.

17. Yokoyama N, Okamura M, Igarashi I. Erythrocyte invasion by Babesia parasites: current advances in the elucidation of the molecular interactions between the protozoan ligands and host receptors in the invasion stage. Vet Parasitol. 2006;138:22-32.

18. Suarez CE, Palmer GH, Jasmer DP, Hines SA, Perryman LE, McElwain TF. Characterization of the gene encoding a 60-kilodalton Babesia bovis merozoite protein with conserved and surface exposed epitopes. Mol Biochem Parasitol. 1991;46:45-52.

19. Dalrymple BP, Casu RE, Peters JM, Dimmock CM, Gale KR, Boese R, et al. Characterization of a family of multi-copy genes encoding rhoptry protein homologues in Babesia bovis, B. ovis and B. canis. Mol Biochem Parasitol. 1993;57:181-92.

20. Skuce PJ, Mallon TR, Taylor SM. Molecular cloning of a putative rhoptry associated protein homologue from Babesia divergens. Mol Biochem Parasitol. 1996;77:99-102.

21. Zhou JL, Jia HL, Nishikawa Y, Fujisaki K, Xuan XX. Babesia gibsoni rhoptry associated protein 1 and its potential use as a diagnostic antigen. Vet Parasitol. 2007;145:16-20.

22. Bhoora R, Quan M, Zweygarth E, Guthrie AJ, Prinsloo SA, Collins NE. Sequence heterogeneity in the gene encoding the rhoptry-associated protein-1 (RAP-1) of Babesia caballi isolates from South Africa. Vet Parasitol. 2010;169:279-88.

23. Yu Q, He L, Zhang WJ, Cheng JX, Hu JF, Miao XY, et al. Molecular cloning and characterization of Babesia orientalis rhoptry-associated protein 1. Vet Parasitol. 2014;205:499-505.

24. Yokoyama N, Suthisak B, Hirata H, Matsuo T, Inou N, Sugimoto C, et al. Cellular localization of Babesia bovis merozoite rhoptry-associated protein 1 and its erythrocyte-binding activity. Infect Immun. 2002;70:5822-6.

25. Mosqueda J, McElwain TF, Stiller D, Palmer GH. Babesia bovis merozoite surface antigen 1 and rhoptry-associated protein 1 are expressed in sporozoites, and specific antibodies inhibit aporozoite attachment to erythrocytes. Infect Immun. 2002;70:1599-603.

26. Figueroa JV, Buening GM. In vitro inhibition of multiplication of Babesia bigemina by using monoclonal antibodies. J Clin Microbiol. 1991;29: 997-1003.

27. Suarez CE, Palmer GH, Hines SA, McElwain TF. Immunogenic B-cell epitopes of Babesia bovis rhoptry-associated protein 1 are distinct from sequences conserved between species. Infect Immun. 1993;61:3511-7.

28. Ushe TC, Palmer GH, Sotomayor L, Figueroa JV, Buening GM, Perryman $L E$, et al. Antibody response to a Babesia bigemina rhoptry-associated protein 1 surface-exposed and neutralization-sensitive epitope in immune cattle. Infect Immun. 1994;62:5698-701.

29. Boonchit S, Xuan X, Yokoyama N, Goff WL, Wagner G, Igarashi I. Evaluation of an enzyme-linked immunosorbent assay with recombinant rhoptry- associated protein 1 antigen against Babesia bovis for the detection of specific antibodies in cattle. J Clin Microbiol. 2002;40:3771-5.

30. Wright IG, Casu R, Commins MA, Dalrymple BP, Gale KR, Goodger BV, et al. The development of a recombinant Babesia vaccine. Vet Parasitol. 1992:44: 3-13.

31. Brown WC, Estes DM, Chantler SE, Kegerreis KA, Suarez CE. DNA and a CpG oligonucleotide derived from Babesia bovis are mitogenic for bovine B cells. Infect Immun. 1998;66:5423-32.

32. Brown WC, Palmer GH. Designing Blood-stage Vaccines against Babesia bovis and B. bigemina. Parasitol Today. 1999;15:275-81.

33. Machado RZ, McElwain TF, Pancracio HP, Freschi CR, Palmer GH. Babesia bigemina: immunization with purified rhoptries induces protection against acute parasitemia. Exp Parasitol. 1999;93:105-8.

34. Niu Q, Bonsergent C, Guan G, Yin H, Malandrin L. Sequence and organization of the rhoptry-associated-protein-1 (rap-1) locus for the sheep hemoprotozoan Babesia sp. BQ1 Lintan (B. motasi phylogenetic group). Vet Parasitol. 2013;198:24-38.

35. Suarez CE, Thompson SM, McElwain TF, Hines SA, Palmer GH. Conservation of oligopeptide motifs in rhoptry proteins from different genera of erythroparasitic protozoa. Exp Parasitol. 1994;78:246-51.

36. Ikadai H, Osorio CR, Xuan X, Igarashi I, Kanemaru T, Nagasawa H, et al. Detection of Babesia caballi infection by enzyme-linked immunosorbent assay using recombinant 48-kDa merozoite rhoptry protein. Int J Parasitol. 2000;30:633-5.

37. Terkawi MA, Thekisoe OM, Katsande C, Latif AA, Mans BJ, Matthee O, et al. Serological survey of Babesia bovis and Babesia bigemina in cattle in South Africa. Vet Parasitol. 2011a;182:337-342.

38. Guan G, Chauvin A, Rogniaux H, Luo J, Yin H, Moreau E. Merozoite proteins from Babesia sp. BQ1 (Lintan) as potential antigens for serodiagnosis by ELISA. Parasitology. 2010a;137:927-938.

39. Moitra P, Zheng H, Anantharaman V, Banerjee R, Takeda K, Kozakai Y, et al. Expression, purification, and biological characterization of Babesia microti apical membrane antigen 1. Infect Immun. 2015;83:3890-901.

40. Guan G, Ma M, Liu A, Ren Q, Wang J, Yang J, et al. A recently identified ovine Babesia in China: serology and seroepidemiology. Parasitol Int. 2012a;61:532-537.

41. McElwain TF, Perryman LE, Davis WC, McGuire TC. Antibodies define multiple proteins with epitopes exposed on the surface of live Babesia bigemina merozoites. J Immunol. 1987;138:2298-304.

42. Mishra VS, Stephens EB, Dame JB, Perryman LE, McGuire TC, McElwain TF. Immunogenicity and sequence analysis of recombinant p58: a neutralization-sensitive, antigenically conserved Babesia bigemina merozoite surface protein. Mol Biochem Parasitol. 1991:47:207-12.

43. Suarez CE, Palmer GH, Hötzel I, McElwain TF. Structure, sequence, and transcriptional analysis of the Babesia bovis rap-1 multigene locus. Mol Biochem Parasitol. 1998:93:215-24.

44. Suarez CE, Palmer GH, Florin-Christensen M, Hines SA, Hötzel I, McElwain TF. Organization, transcription, and expression of rhoptry associated protein genes in the Babesia bigemina rap-1 locus. Mol Biochem Parasitol. 2003;127: $101-12$.

45. Hötzel I, Brown WC, McElwain TF, Rodríguez SD, Palmer GH. Dimorphic sequences of rap-1 genes encode $B$ and CD4+ T helper lymphocyte epitopes in the Babesia bigemina rhoptry associated protein-1. Mol Biochem Parasitol. 1996;81:89-99.

46. Hötzel I, Suarez CE, McElwain TF, Palmer GH. Genetic variation in the dimorphic regions of RAP-1 genes and rap-1 loci of Babesia bigemina. Mol Biochem Parasitol. 1997;90:479-89.

47. Boonchit S, Xuan X, Yokoyama N, Goff WL, Waghela SD, Wagner G, et al. Improved enzyme-linked immunosorbent assay using C-terminal truncated recombinant antigens of Babesia bovis rhoptry-associated protein-1 for detection of specific antibodies. J Clin Microbiol. 2004;42:1601-4.

48. Boonchit S, Alhassan A, Chan B, Xuan X, Yokoyama N, Ooshiro M, et al. Expression of C-terminal truncated and full-length Babesia bigemina rhoptry-associated protein 1 and their potential use in enzyme-linked immunosorbent assay. Vet Parasitol. 2006;137:28-35.

49. Iseki H, Zhou L, Kim C, Inpankaew T, Sununta C, Yokoyama N, et al. Seroprevalence of Babesia infections of dairy cows in northern Thailand. Vet Parasitol. 2010;170:193-6.

50. Terkawi MA, Huyen NX, Shinuo C, Inpankaew T, Maklon K, Aboulaila M. et al. Molecular and serological prevalence of Babesia bovis and Babesia bigemina in water buffaloes in the northeast region of Thailand. Vet Parasitol. $2011 \mathrm{~b}$; 178:201-207. 
51. Guan G, Moreau E, Liu J, Ma M, Rogniaux H, Liu A, et al. BQP35 is a novel member of the intrinsically unstructured protein (IUP) family which is a potential antigen for the sero-diagnosis of Babesia sp. BQ1 (Lintan) infection. Vet Parasitol. 2012b;187:421-430.

52. Guan G, Liu J, Liu A, Li Y, Niu Q, Gao J, et al. A member of the HSP90 family from ovine Babesia in China: molecular characterization, phylogenetic analysis and antigenicity. Parasitology. 2015;142:1387-97.

53. Böse R, Jacobson RH, Gale KR, Waltisbuhl DJ, Wright IG. An improved ELISA for detection of antibodies against Babesia bovis using either a native or a recombinant B. bovis antigen. Parasitol Res. 1990;76:648-52.

54. Böse R, Jorgensen WK, Dalgliesh RJ, Friedhoff KT, de Vos AJ. Current state and future trends in the diagnosis of babesiosis. Vet Parasitol. 1995;57:61-74.

55. Bakheit MA, Seitzer U, Mbati PA, Ahmed JS. Serological diagnostic tools for the major tick-borne protozoan diseases of livestock. Parassitologia. 2007;49 Suppl 1:53-62.

56. Terkawi MA, Huyen NX, Wibowo PE, Seuseu FJ, Aboulaila M, Ueno A, et al. Spherical body protein 4 is a new serological antigen for global detection of Babesia bovis infection in cattle. Clin Vaccine Immunol. 2011c;18:337-342.

57. Wang JM, Ma ML, Liu AH, Ren QY, Li AY, Liu ZJ, et al. A seroepidemiological survey of Chinese Babesia motasi for small ruminants in China. Parasitol Res. 2013:112:2387-91.

58. Niu Q, Liu Z, Yang J, Yu P, Pan Y, Zhai B, et al. Genetic diversity and molecular characterization of Babesia motasi-like in small ruminants and ixodid ticks from China. 2016. Infect Genet Evol, in press.

59. Teng K, Jiang Z. Economic insect fauna of China. fasc 39 Acari: Ixodidae. 1991. Science Press, Beijing. (In Chinese)

60. Guan G, Moreau E, Liu J, Hao X, Ma M, Luo J, et al. Babesia sp. BQ1 (Lintan): molecular evidence of experimental transmission to sheep by Haemaphysalis qinghaiensis and Haemaphysalis longicornis. Parasitol Int. 2010b;59:265-257

61. Yang ZJ, Long T, Jiao N, Wang BA, Zhao SK. Treatment of Small-tailed babesiosis. Henan Agr Sci. 2003;12:58-59. (In Chinese)

62. Li ZH, Zhang GW, Zhao DY. A case of ovine piroplasmoisis, diagnosis and treatment. Shanxi Agri. 2006:11:27 (In Chinese).

63. Zhang $\mathrm{CL}$, Liao HF, Han QP, Bao YL. Diagnosis and treatment of goat babesiosis. Yuannan J Animal Sci Vet Medi. 2010;4:19-20 (In Chinese).

\section{Submit your next manuscript to BioMed Central and we will help you at every step:}

- We accept pre-submission inquiries

- Our selector tool helps you to find the most relevant journal

- We provide round the clock customer support

- Convenient online submission

- Thorough peer review

- Inclusion in PubMed and all major indexing services

- Maximum visibility for your research

Submit your manuscript at www.biomedcentral.com/submit 